\title{
Policy Evaluation on Regional Emission Trade Market-A Simulation Analysis
}

\author{
Jun Zeng ${ }^{1, a}$, Ming Zhou ${ }^{1, *}$, Yan-Chun Pan ${ }^{1, b}$, Mei-Rong Zhou ${ }^{1, c}$ \\ Ruo-Nan Sun ${ }^{1, d}$ \\ ${ }^{1}$ College of Management, Shenzhen University, Shenzhen 518060, P.R. China \\ azengjun19881202@126.com, ${ }^{\text {bpan_yc@163.com, }{ }^{c} 1953275607 @ q q . c o m,{ }^{d} 916665565 @ q q . c o m}$ \\ ${ }^{*}$ Corresponding author
}

Keywords: Carbon policy, Policy evaluation, Analysis of variance, Multiple regression analysis.

\begin{abstract}
With greatly enhanced economic development and human material, social development and the contradiction between the human bearing capacities of the environment is increasingly highlighted, in response to dramatic changes in climate, various countries have proposed a series of controlling greenhouse gas reduction exclusive strategies and initiatives. Carbon emission trade programs started since 2011 in China, seven cities/provinces were chosen as pilot areas, and a unified national carbon emission trade market is planned for commission at the end of 2016. The attendant problems of various carbon emission policies are validation and appropriateness. This study simulates the enterprises participating in a dynamic and uncertain carbon trade market and making carbon resource acquisition/disposition decisions under the impact of government policies regarding the control, quota allocation and auction, and emission reduction. It summarized, characterized, and analyzed the efficiency of the government policies under a Cap and Trade (C\&T) condition in the management of a regional emission trade market.
\end{abstract}

\section{Background}

To effectively control air pollution and promote green production/service, China has established regional emission trade markets at several "trial cities". These systems operate under the conditions of "Cap and Trade" [1]. Cap and trade ( $\mathrm{C} \& \mathrm{~T})$ refers to the government to determine the total amount of emissions for $\mathrm{CO} 2$ in a region, then allocates to companies (quotas) in the region with the limit of the total amount of emission allowances. Corporate carbon emissions cause by normal production activities are strictly monitored; and companies can purchase additional emissions allowances through carbon trading market to meet their needs superovulation, or sell its surplus quotas directly to obtain economic benefits.

Under C\&T framework, Anger (2008) pointed out that the price of carbon emissions is affected by carbon emission rights allocation mechanism, the more stringent distribution, the higher the price of carbon emission rights [2]. Fankhausera and Hepburn (2010) considered a longer commitment period spanning across storage of carbon emission rights limited temporal borrowing quota auction, carbon stocks and carbon prices, making carbon emissions price fluctuations predictable and emission trading market flexible [3]. Benz and Truck (2009) studied in the EU ETS emissions on the dynamics of prices, considered marginal abatement costs, fines cost, and transaction time interval, carbon storage and lending mechanisms had an impact on carbon emission rights prices [4]. Montgomery (1972) research indicates that in a variety of ways to cut emissions, the cost of the lowest emissions trading, if the emission rights market is perfectly competitive, the market can achieve competitive equilibrium, then the whole area of pollution control can achieve total cost minimized[5]. Ao Yang, Liu Ji and Wu Yi was (2014) through the establishment of a dynamic stochastic general equilibrium (DSGE) model, compare the same emission reduction targets under no carbon policy, carbon intensity, carbon caps and carbon taxes four different carbon emissions the merits of the policy, were analyzed at $20 \%$ and $40 \%$ target, the impact of these four 
policies on macroeconomic variables steady-state value [6]. Li Hao et al. (2012) using multi-agent technology to verify the impact of carbon emission allocations and the full market price of carbon trading to corporate priorities and strategies [7]. Deng Xiang et al. (2012) describes the policies and the latest trends in the field of implementation of EU carbon emissions, and proposed EU Emissions Policy Implications for China-related policy formulation.

\section{Variables setting}

This paper analyzes the four types of carbon emissions policy, as shown in Table 1, X1 represents the total control policy, X2 represents carbon allowance auction's policy, X3 represents self-purification and emission reduction policy, X4 represents superovulation punishment policy. First summarizes the types of carbon emissions policy, portrayed from the dimensions to control the emission reduction targets for the purpose of emission reduction strategies and to improve the purpose of policy and research impact of these two types of strategies for system performance; Study total control policy through policy detail function angle, the carbon allowance auction's policy, self-purification and emission reduction policy, a policy of punishment superovulation respectively interactions affect system performance as well as between these four policies for system performance influence.

Tab. 1 Experiment variables

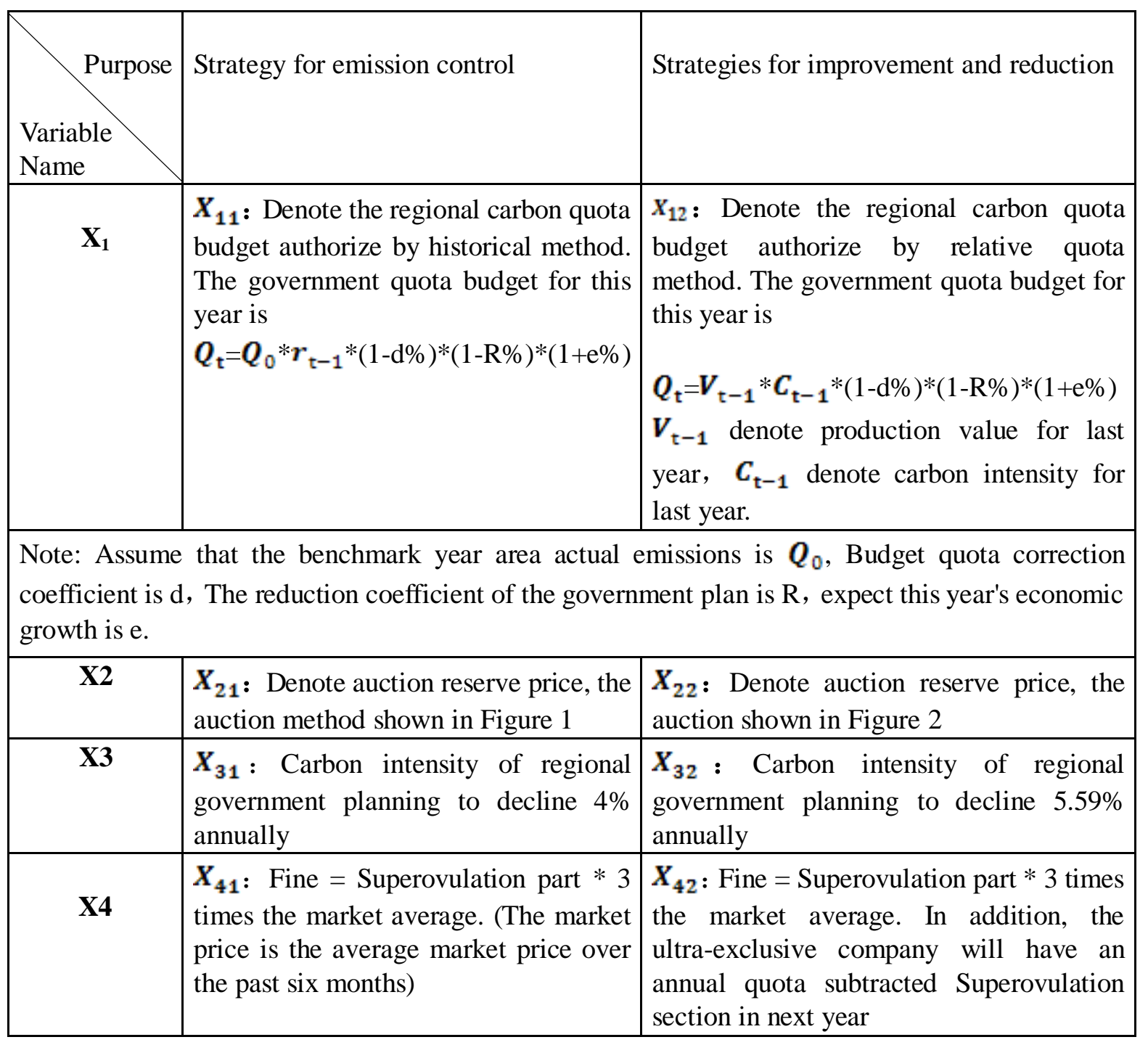




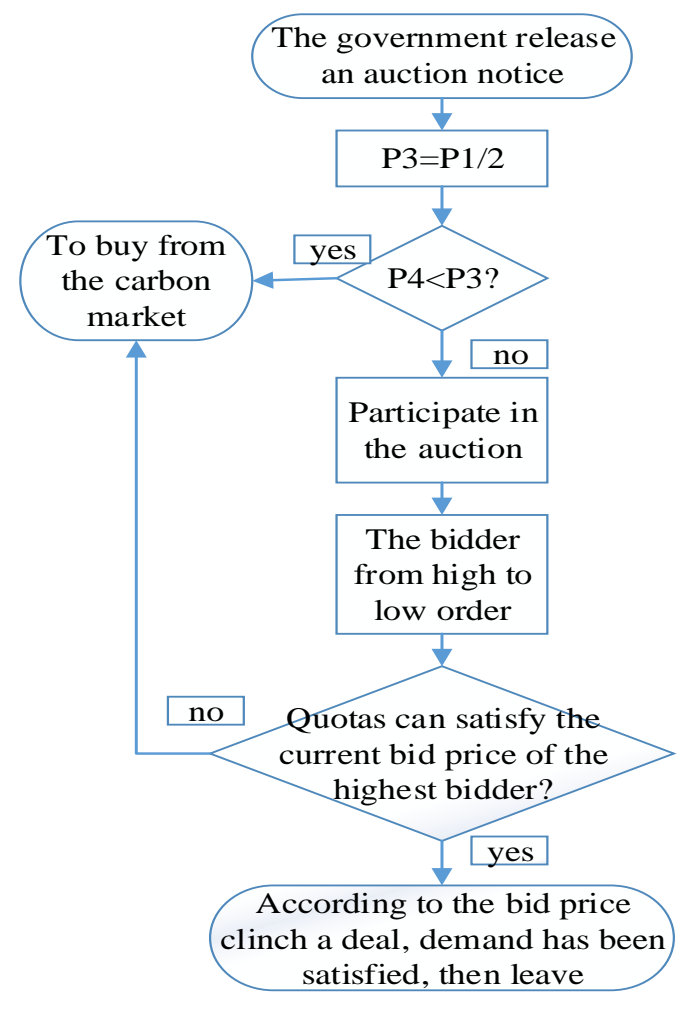

Fig. 1

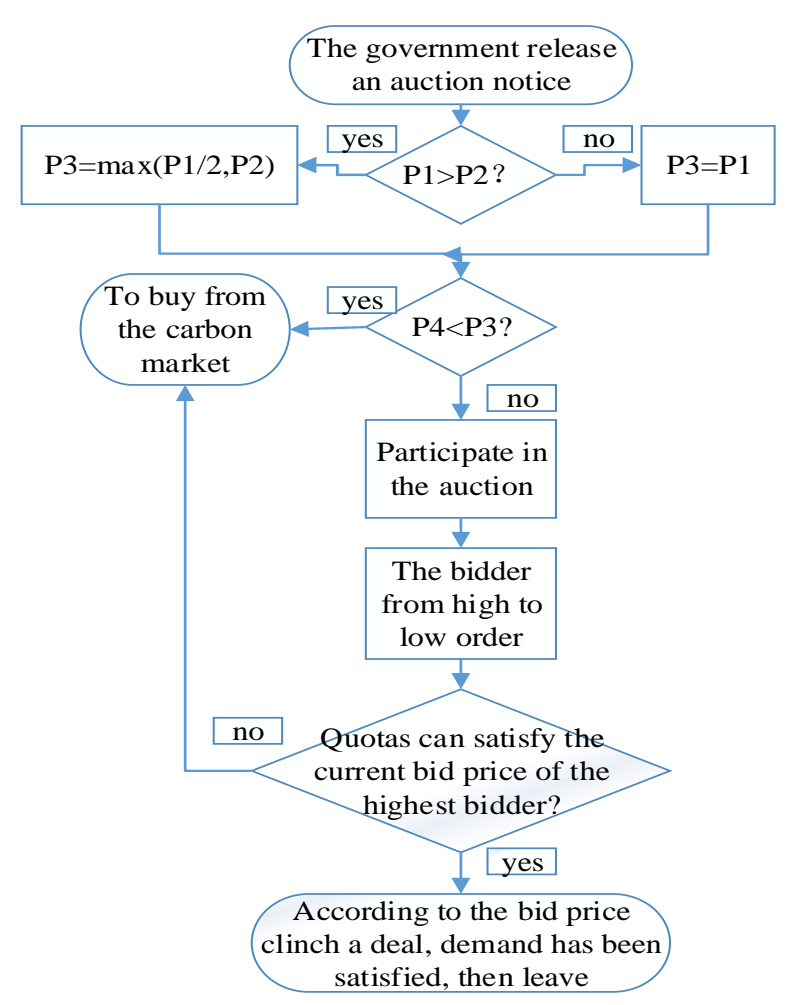

Fig. 2

Where P1 is the day before the auction notice published in the carbon market price; P2 the regional average cost of reducing emissions in previous year; P3 auction reserve price; P4 the buyer's expected price; $\max (\mathrm{P} 1 / 2, \mathrm{P} 2)$ to determine whichever value is greater, $\mathrm{P} 1 / 2$ or $\mathrm{P} 2$.

\section{Analysis of variance}

According to the variable settings, we designed a 24 factorial experiment, and conducted a total of 16 simulated combinations. Each simulation experiment was repeated 50 times. The simulation model used in the study was in days' time units and the length of each replication was set 72 months. This study selected the total actual annual emissions as the statistical output indicators.

Tab. 2 Analysis of variance of significant policy factors on emission trade market

\begin{tabular}{|l|l|l|l|l|l|}
\hline source & III type of sum of squares & \multicolumn{1}{|c|}{ df } & \multicolumn{1}{|c|}{ Mean square } & \multicolumn{1}{c|}{ F } & Sig. \\
\hline Calibration model & $235035042773722.530 \mathrm{a}$ & 15 & 15669002851581.502 & 167.091 & .000 \\
\hline intercept & 205413860857468032.00 & 1 & 205413860857468032.000 & 2190490.712 & .000 \\
\hline $\boldsymbol{X}_{\mathbf{1}}$ & 42964775882115.600 & 1 & 42964775882115.600 & 458.167 & .000 \\
\hline $\boldsymbol{X}_{\mathbf{2}}$ & 297628626993.727 & 1 & 297628626993.727 & 3.174 & .075 \\
\hline $\boldsymbol{X}_{\mathbf{3}}$ & 173440554012755.940 & 1 & 173440554012755.94 & 1849.534 & .000 \\
\hline $\boldsymbol{X}_{\mathbf{4}}$ & 46360752272.133 & 1 & 46360752272.133 & .494 & .482 \\
\hline $\boldsymbol{X}_{\mathbf{1}} * \boldsymbol{X}_{\mathbf{2}}$ & 401512242926.267 & 1 & 401512242926.267 & 4.282 & .039 \\
\hline $\boldsymbol{X}_{\mathbf{1}} * \boldsymbol{X}_{\mathbf{3}}$ & 17264956275625.582 & 1 & 17264956275625.582 & 184.110 & .000 \\
\hline $\boldsymbol{X}_{\mathbf{1}} * \boldsymbol{X}_{\mathbf{4}}$ & 12685118611.442 & 1 & 12685118611.442 & .135 & .713 \\
\hline $\boldsymbol{X}_{\mathbf{2}} * \boldsymbol{X}_{\mathbf{3}}$ & 408674841782.019 & 1 & 408674841782.019 & 4.358 & .037 \\
\hline $\boldsymbol{X}_{\mathbf{2}} * \boldsymbol{X}_{\mathbf{4}}$ & 3276745914.575 & 1 & 3276745914.575 & .035 & .852 \\
\hline $\boldsymbol{X}_{\mathbf{3}} * \boldsymbol{X}_{\mathbf{4}}$ & 2286679933.946 & 1 & 2286679933.946 & .024 & .876 \\
\hline error & 73519812729723.280 & 784 & 93775271338.933 & & \\
\hline total & 205722415712971552.00 & 800 & & & \\
\hline Calibrate total & 308554855503445.800 & 799 & & & \\
\hline
\end{tabular}


Table 2 showed the policy variables $\mathrm{X} 1, \mathrm{X} 3, \mathrm{X} 1 * \mathrm{X} 2, \mathrm{X} 1 * \mathrm{X} 3, \mathrm{X} 2 * \mathrm{X} 3$ that have significant impact on the actual amount of regional annual carbon emissions. While the interactions of other variables and variables such as $\mathrm{X} 2, \mathrm{X} 4$ influence and $\mathrm{X} 1 * \mathrm{X} 2 * \mathrm{X} 3$ and other regional of the actual amount of annual carbon emissions were not significant. As an example to compare the difference between experimental levels of the variable X1 (total control of policy) on the actual annual carbon emission, we show the results of independent sample $t$ test in the Table 3.

From Table 3, the total control of policy (X1), its emissions reduction strategy for the purpose of improving the budget is a carbon quota regions with a relatively Quota Act approved on greater impact of the actual amount of annual carbon emissions regional, because the average total annual actual emissions regional at this time is smaller.

Tab. 3 Independent sample t-test of total control of policy

\begin{tabular}{|c|c|c|c|c|c|c|c|c|c|}
\hline & \multicolumn{2}{|c|}{$\begin{array}{c}\text { Levene test for } \\
\text { variance equation }\end{array}$} & \multicolumn{7}{|c|}{$\mathrm{T}$ test for mean value equation } \\
\hline & \multirow[t]{2}{*}{$\mathrm{F}$} & \multirow[t]{2}{*}{ Sig. } & \multirow[t]{2}{*}{$\mathrm{t}$} & \multirow[t]{2}{*}{$\mathrm{df}$} & \multirow[t]{2}{*}{$\begin{array}{l}\text { Sig.(doub } \\
\text { le side) }\end{array}$} & \multirow[t]{2}{*}{$\begin{array}{l}\text { mean value } \\
\text { D-value }\end{array}$} & \multirow[t]{2}{*}{$\begin{array}{l}\text { Standard } \\
\text { error value }\end{array}$} & \multicolumn{2}{|c|}{$\begin{array}{l}\text { Confidence interval } \\
\text { for } 95 \% \text { difference }\end{array}$} \\
\hline & & & & & & & & $\begin{array}{l}\text { Lower } \\
\text { limit }\end{array}$ & $\begin{array}{l}\text { Upper } \\
\text { limit }\end{array}$ \\
\hline $\begin{array}{l}\text { If variance } \\
\text { equals }\end{array}$ & 173.7 & .000 & 11.3 & 798 & .000 & 463490.9 & 40793.3 & 383416.0 & 543565.9 \\
\hline $\begin{array}{l}\text { If variance } \\
\text { not equals }\end{array}$ & & & 11.3 & 699 & .000 & 463490.9 & 40793.3 & 383398.8 & 543583.1 \\
\hline
\end{tabular}

\section{Correlation analysis and multiple regression analysis}

For the significance level of 0.01 , we found, via a correlation analysis, that the total control of policy (X1), carbon allowance auction's policy (X2), self-purification and emission reduction policies (X3) and over-emission penalty policy (X4) These four policies are significantly related to each other, while the correlation between high and low: X2 and X3 is low correlation ; X2 and X4, $\mathrm{X} 1$ and $\mathrm{X} 2, \mathrm{X} 3$ and $\mathrm{X} 4, \mathrm{X} 1$ and $\mathrm{X} 4, \mathrm{X} 1$ and $\mathrm{X} 3$ are associated with moderate. This shows that carbon emissions trading system in a variety of policy is not completely independent, but interrelated.

We also briefly show a regression analysis that estimates the dependent relationship between model's major outputs (e.g. total carbon emissions) and input or policy variables. Through analysis of variance, we know that only the total control of the interaction of policy (X1), self-purification and emission reduction policies (X3), the interaction of the total control of policy and carbon quota auctions policies $(\mathrm{X} 1 * \mathrm{X} 2)$, the interaction of self-purification/emission reduction policies and total control policies $(\mathrm{X} 1 * \mathrm{X} 3)$, carbon allowance auction's policy and the policy of self-purification and emission reduction $(\mathrm{X} 2 * \mathrm{X} 3)$ regional annual real effect of total carbon emissions are significant, so the regional annual government budget quota (x1), the total amount of interactive self-purification (x2), the actual completion of the annual regional budget and the annual government quota and actual annual regional quota auctions out of the area action (x3), the total government budget purification annual regional quotas actually finished the year with the interaction region $(x 4)$, the interaction of self-purification of the total annual quota annual regional and regional real auction of the actual completion of (x5) to argument, while the total amount of actual annual emissions area (y) as the dependent variable regression analysis model to quantitatively analyze the relationship between them. Regression model as follows:

$$
\mathrm{y}=\mathrm{b}+\mathrm{a} 1 * \mathrm{x} 1+\mathrm{a} 2 * \mathrm{x} 2+\mathrm{a} 3 * \mathrm{x} 3+\mathrm{a} 4 * \mathrm{x} 4+\mathrm{a} 5 * \mathrm{x} 5
$$

Where a1, a2, a3, a4, a5 is the regression coefficients, b is a constant term. Regression analysis 
results are shown in Table 4.

Tab. 4 regression coefficients and constant terms (unit: ton)

\begin{tabular}{|c|c|c|c|c|c|}
\hline \multirow{2}{*}{ Model } & \multicolumn{2}{|c|}{ Non-standardized coefficient } & standardized coefficient & \multirow{2}{*}{ Sig. } \\
\cline { 2 - 4 } & $\mathrm{B}$ & Standard error & trial & & \\
\hline constant & 17629607.26 & 1417973.227 & & 12.433 & .000 \\
\hline $\mathbf{X 1}$ & .046 & .104 & .045 & .446 & .655 \\
\hline $\mathbf{X 3}$ & -17.144 & 1.533 & -3.482 & -11.18 & .000 \\
\hline $\mathbf{X 1} * \mathbf{X 2}$ & $-1.839 \mathrm{E}-007$ & .000 & -.217 & -2.879 & .004 \\
\hline $\mathbf{X 1} * \mathbf{X 3}$ & $9.113 \mathrm{E}-007$ & .000 & 2.376 & 8.756 & .000 \\
\hline $\mathbf{X 2} * \mathbf{X 3}$ & $3.417 \mathrm{E}-006$ & .000 & .316 & 2.791 & .005 \\
\hline
\end{tabular}

Estimated regression relation was formed based on the Table 4:

$$
y=17629607.26+0.046 x 1-17.144 \times 2-1.839 \mathrm{E}-007 \times 3+9.113 \mathrm{E}-007 \mathrm{x} 4+3.417 \mathrm{E}-006 \times 5
$$

Where $\mathrm{y}$ represents the actual total annual carbon emissions area, $\mathrm{x} 1$ represents the regional government budget quota year(X1)), $\mathrm{x} 2$ the total amount of annual regional self-purification actually completed(X3, x3 the area annual government budget and annual regional quota auctions of the actual interaction of quota $(\mathrm{X} 1 * \mathrm{X} 2), \mathrm{x} 4$ the interaction of self-purification of the total area annual government budget and annual regional quota actually completed (X1*X3), and $\mathrm{x} 5$ the total amount of annual regional interaction purification actual auction of the quota year and the actual completion of the area $(\mathrm{X} 2 * \mathrm{X} 3)$.

\section{Summary}

Total amount of actual carbon emissions for a measure of annual regional terms, the results from the analysis of variance and test point of view, in order to reduce emissions for the purpose of improving the ratio of emissions control strategy for the purpose of regional policy actual annual emissions of carbon greater total effect, which results in line with our expectations. From the results of the regression analysis point of view, of the total amount of actual annual emissions impact area descending order is the interaction of self-purification and emission reduction policies (X3), policy and self-purification and emission reduction of the total control of policy ( $\mathbf{X 1} * \mathbf{X 3}$ ), the interaction of the interaction with the carbon allowance auction policy aspects of the policy of total control of $(\mathbf{X} 1 * \mathbf{X} 2)$, carbon allowance auction's policy and the policy of self-purification and emission reduction $(\mathbf{X} 2 * \mathbf{X 3})$ and total control of policy $(\mathbf{X 1})$.

Finally the authors would like to acknowledge that the research is partially funded by the Natural Science Foundation of China (NSFC) under grant codes 71172057 and 71272089.

\section{Reference}

[1] IPCC, 2007. Climate Change 2007: The Physical Science Basis. Cambridge University Press, UK. pp. 1-18. http://www.ipcc.ch/pdf/assessment-report/ar4/wg1/ar4-wg1-spm.pdf.

[2] Anger, N. and U. Oberndorfer. Firm Performance and Employment in the EU Emissions Trading Scheme: An Empirical Assessment for Germany [J]. Energy Policy, 2008, 36: 12-22.

[3] Samuel Fankhausera and Cameron Hepburn. Designing carbon markets Part I: Carbon markets in time [J]. Energy Policy, 2010, 31.

[4] Benz, E. and S. Truck. Modeling the Price Dynamics of CO2 Emission Allowances [J]. Energy Economics, 2009, 31: 4-15.

[5] Montgomery, D. Markets in Licenses and Efficient Pollution Control Programs [J]. Journal of 
Economic Theory, 1972, 5: 395-418.

[6] Yang A, Liu J X, Wu X Y. Carbon emissions reduction targets and policy effect research based on DSGE model [J]. Resource science, 014,39(7)1425-1461.

[7] Li H, Zhao D Y. Based on the Agent's carbon emissions trading mechanism modeling and simulation [J]. Computer Engineering and Applications,2012,48(25):9-14.

[8] Carbon emissions trading management provisional regulations of Shenzhen 2014.

[9] Douglas C. Montgomery. Design and Analysis of Experiments [M]. UG/GGS Information Services, Inc. 2001, 218-276.

[10] Wei Y M etc. Some countermeasures and Suggestions about China's carbon emissions [J]. Advances in Climate Change Research ,2006,2(1):15-20.

[11] He W etc. Optimization design of experiment method and data analysis [M]. Beijing: chemical industry press, 2012:29-60, 103-118.

[12] Lou W etc. Low carbon economy planning theory, method, model [M] Beijing: social sciences academic press, 2011, 328-335. 